\title{
Implantable Prosthesis of Osseous Conduction (BAHA): Case Report
}

\author{
Prótese Implantável de Condução Óssea (BAHA): Relato de Caso
}

\author{
Izabella Vince Garcia Pedriali*, Maurico Buschle **, Rita de Cássia Mendes***, \\ André Luiz Ataíde $* * * *$, Rodrigo Pereira $* * * * *$, Trissia Maria Farab Vassoler $* * * * *$, \\ José Fernando Polanski $* * * * * * *$, Angela Ribas $* * * * * * * *$, Claudia Mittelmann Stumpf $* * * * * * * * *$, \\ Raquel Alves Nobre $* * * * * * * * *$, Roberta Daroit $* * * * * * * * * * *$.
}

\begin{abstract}
* Master in Communication Disorders. Phonoaudiologist.
** Master in Surgical Clinics - PR's. Assistant Professor at UFPR's Department of Ophthalmology-Otorhinolaryngology (OFT-ORL)

*** Master in Surgical Clinics - UFPR's. Otorhinolaryngologist Doctor at UFPR's Clinical Hospital.

**** Otorhinolaryngologist Doctor. Predecessor in Otology in Residence at Santa Casa de Curitiba's ORL and President of Fisch Foundation in Brazil

*****: Post-Graduation Coordinator in Otorhynolaryngology at Pequeno Príncipe Hospital. Post-Graduation Coordinator at Otorhinopediatrics at Pequeno Príncipe Hospital. ****** Specialized in Otorhinolaryngology from the Brazilian Society of Otorhinolaryngology and Cervicofacial Surgery. Otorhinolary ngologist Doctor.

******** Master in Otorhinolaryngology from Federal University of Sao Paulo. Predecessor in Medical Residence in Otorhy nolaryngology at Evangelical Hospital of Curitiba

********* Doctor in Environment and Urban Development. Phonoaudiologist.

********** Specialized in Audiology. Phonoaudiologist.

*********** Specialized in Clinical and Educational Audiology from HRAC-USP. Phonoaudiologist

***********: Specialized in Audiology from UTP. Phonoaudiologist.

Institution: Iguaçu Hospital.

Curitiba / PR - Brazil

Mailing address: Izabella Vince Garcia Pedriali - Rua Urbano Lopes, 238 - Apto. 1101 - Bairro Cristo Rei - Curitiba / PR - Brazil - ZIP Code: $80035-520$ - Telephone: (+55 41) 3527-4327 - E-mail: ipmacedo @uol.com.br

Article received on January 26, 2010. Article approved on May 2, 2010
\end{abstract}

\section{SUMMARY}

Introduction:

Objective:

Method:

Final commentaries:

Keywords:

\section{RESUMO}

Introdução:

Objetivo:

Método:

Comentários Finais:

Palavras-chave:
The implantable prosthesis of osseous conduction (BAHA) is deemed to be an excellent option in the auditory rehabilitation of patients with conductive and mixed hearing loss, unilaterally or bilaterally, and unilateral sensorineural hearing loss. It has been a good advantage over the conservative bone conduction apparatus and those of individual sound-amplifier apparatus (ISAA), when their usage becomes unfeasible because of chronic otitis externa, which has a hard clinic control.

To introduce the first BAHA case performed in Brazil, as duly authorized by ANVISA (National Agency for Sanitary Surveillance), to rehabilitate the mixed hearing loss with occurrences of chronic otitis externa. 50-year-old female patient with right-ear moderate and left-ear severe hearing loss, bilateral tinnitus derived from otosclerosis, was submitted to 04 surgeries of stapedotomy and unable to use ISAA as a result of otorrhea and bilateral otalgia. The medical and audiological evaluation indicated the benefit of using BAHA. Having surgery been performed and BAHA implemented, the patient showed a significant improvement in audiometric thresholds, speech perception and distinction, as well as she declared to be extremely satisfied with the esthetic factor.

BAHA surgical process is safe, simple and swift, thus providing excellent audiological results and a higher degree of satisfaction to patients.

prosthesis and implants, hearing loss, otitis externa.

A Prótese Implantável de Condução Óssea (BAHA) consiste em uma excelente opção na reabilitação auditiva de pacientes com perda auditiva condutiva e mista uni ou bilateral, e sensorioneural unilateral. Tem sido uma alternativa vantajosa sobre os aparelhos de condução óssea convencionais e os aparelhos de amplificação sonora individuais (AASI) quando o uso dos mesmos fica impossibilitado pela presença de otite externa crônica de difícil controle clínico.

Apresentar o primeiro caso de BAHA realizado no Brasil, após a autorização da ANVISA, para a reabilitação da perda auditiva mista com episódios de otite externa crônica.

Paciente do sexo feminino, 50 anos, com perda auditiva de grau moderado à direita e severo à esquerda, zumbido bilateral, decorrente de otosclerose, submetida a quatro cirurgias de estapedotomia e com impossibilidade de uso de AASI devido a otorreia e otalgia bilateral. A avaliação médica e audiológica indicaram o benefício do BAHA. Realizada a cirurgia e implantação do sistema BAHA, a paciente apresentou melhora significativa nos limiares audiométricos, na percepção e discriminação da fala, além de relatar extrema satisfação relacionada ao fator estético.

O processo cirúrgico do BAHA é seguro, simples e rápido, proporcionando excelentes resultados audiológicos e alto grau de satisfação por parte dos pacientes.

próteses e omplantes, perda auditiva, otite externa. 


\section{INTRODUCTION}

The osseointegrated implants were firstly introduced to clinical practice in Sweden in the 1970's, and they have ever since been widely accepted in such areas as dentistry, maxillofacial surgeries, and reconstructing and orthopedic surgeries (1). The Bone Anchored Hearing Aid (BAHA) system, which was originally used by Tjellstrom and his team in Sweden in 1977 (2), made the prospect of osseointegrated implants renowned in the area of otology.

BAHA system is comprised of two major parts: a titanium screw with an abutment implanted in the cortical part of the mastoid bone and one external unit named processor, which is connected to the abutment. The processor is intended to receive the environmental sounds and convert them into a mechanical energy, what is turned into vibration and transmitted to the abutment, which, in turn, shall stimulate the cortical part of the temporal bone. This vibration is absorbed by the skull and directly stimulates the cochleas without involving the air hearing conduction, i.e., the external acoustic meatus and the middle ear. In some special occasions, such as surgeries on small children, the surgery can be performed in two different times: firstly, by placing the titanium screw and, secondly, by coupling the abutment with this osseointegrated screw.

The titanium screw is surgically implemented, and this procedure can be performed by way of a local anesthesia. The processor shall be inserted only after the osseointegration period, which is three months for adults and six months for children. The processor is easily connected and disconnected by the patient him/herself.

Although it has been long used in Europe and the United States, in Brazil BAHA system has been recently used, and it has a scarce national publication and only a few surgical cases. The team at the Audiological Diagnostic Center of Iguaçu Hospital (CDAH) in Curitiba has been the first one to implant BAHA after it has been authorized by the National Agency for Sanitary Surveillance.

In the meantime, the team faced some difficulties with respect to methodology of audiological evaluation of the different hearing loss cases on BAHA candidates. This fact led to understanding that it is urgent to develop a protocol to audiologically evaluate and follow-up with patients who are candidates to the procedure.

The present study intends to show the first case of BAHA performed in Brazil, as duly approved by ANVISA, having the surgery been performed by Hospital Iguaçu's team, as well as to describe the protocol used during the service. The research was approved by the Ethical
Committee of Tuiuti University of Parana under the number CEP-UTP 047/09, and the patient has signed a term of free and clarified consent, allowing the audiological findings and images presented herein to be divulged.

\section{LITERATURE'S REVISION}

BAHA system is indicated to patients with conductive and mixed hearing loss. The average bone conduction in frequencies of $0.5,1,2$ and $3 \mathrm{kHz}$ must be equal to or above 45 cBNA for the abutment-coupled processor, or as high as $65 \mathrm{dBNA}$ for the box processor. A more recent indication is for patients with unilateral sensorineural hearing loss or Single Sided Deafiness (SSD), presenting contralateral ear with an average bone conduction equal to or above 20 dBNA (3).

Conductive and mixed hearing losses are highly prevailing disorders that can be either treated with surgical techniques or rehabilitated by an individual sound-amplifier apparatus (ISAA). There is, however, a subgroup of patients who are not entitled to a surgical treatment or utilize ISAA by a number of reasons, some of which are agenesis or stenosis of external acoustic meatus, rebel causes with regard to medical and/or surgical treatments of chronic otitis media, chronic otitis externa and open cavity mastoidectomy, among others.

The crown prostheses of bone conduction, mostly indicated for this population, show such hassles as skin irritation due to unstopping pressure in the support place, extremely bad esthetics, and difficulty in maintaining the crown well-positioned in children, for it is easily removable (4). BAHA can overcome all these hassles because it does not place any pressure on skin, but it is discreet and esthetically well-accepted instead, besides being safely tightened to the implant, always in the right place of stimulation (5).

BAHA system presents some outstanding results in cases of conductive and mixed hearing disorders, despite having some restraints on the gain provided to the sensorial component of mixed hearing loss (6).

\section{Case Report}

VLVM, 50-year-old female, presented a moderate left-ear and severe right-ear mixed hearing loss, both of which with ascending configurations and progressive characteristics, caused by bilateral osteosclerosis. The patient appeared at CDAHI after being submitted to three surgeries of stapedotomy on the right ear and one surgery on the left one, all of which were unsuccessful, and subsequent 
worsening of the hearing thresholds. She mentioned a continual tinnitus in the right ear, which was more noticeable during silence, deemed to have a medium impact according to the visual analogue scale (VAS) and vertigo when placing and using ISAA.

She did not actually use ISAA, due to showing chronic otitis externa associated with otorrhea and otalgia.

\section{Pre-Surgical Evaluation}

In the pre-surgical evaluation, medical consultation, audiological and psychological evaluation, and an evaluation protocol for tinnitus were performed, consisting of: visual analogue scale, THI (Tinnitus HandicapInventory), Tyler Activities (characteristics related to concentration, emotions and hearing) and Tyler Handicap (factor $1=$ social, emotional and behavioral, factor $2=$ hearing and factor $3=$ prospect of life).

After the first otorhinolaryngological consultation, in which otoscopy clearly showed otitis externa, edema and purulent secretion in the external acoustic meatus, caused by ISAA, and normal tympanic membranes, it has been indicated an ear tomography and an audiological evaluation composed of pure-tone threshold audiometry (Figure 1), logoaudiometry, immitance audiometry, brainstem auditory evoked potential test (AEP), vectoelectronystagmograph and an open-field audiometry. The latter was performed in three test situations: 1) patient without amplifiers; 2) by using the BAHA tester that is available jointly with the system Kit; 3) with the hearing prosthesis used by the patient.

The image test found permeable cochleas and a medium metallic prosthesis in the right vestibule.

The evaluation with BAHA tester was performed with the arch-coupled processor, providing the patient with a hearing sensitivity caused by the processor vibration (3). By way of an open-field audiometry, pure-tones thresholds issued by a lateral acoustic box were evaluated, and a 60-dBNA monosyllable word-distinction test was performed with a concurring 55-dBNA speech noise before the patient. An external test has also been performed, in which the patient stayed with the tester for one day, using it on the right side during the morning and on the left side during the afternoon.

After the patient's exams were analyzed, she has been indicated to use BAHA Cochlear Divine on her left ear, which is the ear with best bone conduction thresholds and the side preferred by the patient during the external test.

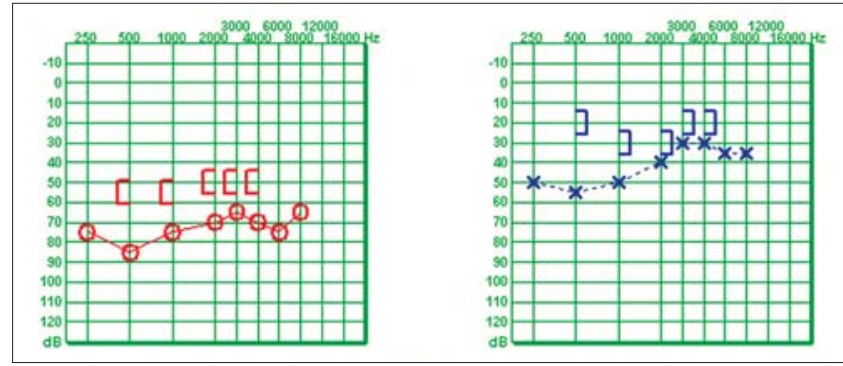

Figure 1. Pre-surgical pure-tone threshold audiometry Better bone conduction in the left ear, side preferable to use BAHA, according to the patient.

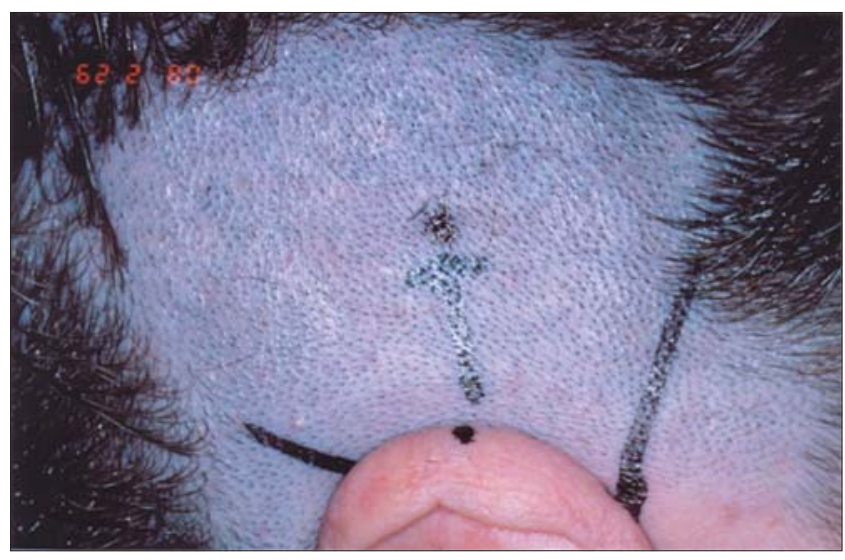

Figure 2. Previous localization of the site where implant shall be installed.

The evaluation results were explained and the patient was guided with respect to the risks and benefits of the surgery. The patient signed both a term of consent and an authorization for the images to be used in this work.

\section{The surgery}

The surgery was performed on February 28, 2008 by a one-time method, in which the screw and the abutment are connected and placed in the same surgical time. A local anesthesia was performed without any intercurrence.

\section{Description of surgical technique}

1- Patient under intravenous sedation, in dorsal decubitus, with head lateralization;

2- Trichotomy and local antisepsis;

3- Local infiltration with adrenaline and lidocaine solution 1:100000;

4- Previous location of the place where the implant shall be fixed, at $5-5.5 \mathrm{~cm}$ of the external acoustic meatus over a line with a $45^{\circ}$ angle to the horizontal axis of CAE and skin marking with a surgical pen (Figure 2); 
5- Drawing of a quadrangular flap with anterior pedicle deepening in the subcutaneous, however without removing periosteum;

6- Incision in the central area of the periosteum and lateral dilatation of this periosteum;

7- Drilling with a 3-mm-deep drill bit, perpendicularly to the bone and irrigated by saline solution;

8- Verification of the depth of drilling and likely contact with dura mater and, in case there is still a texture of bone, drilling with a 4 -mm-drill bit is performed;

9- Drilling with a drill 'countersink' to stretch the drilling onto the accurate diameter of implant (Figure 3);

10-Scraping with a bistoury the pillar flap follicles and narrowing both the subcutaneous flap with dermatomes and the areas adjoining the flap by using an ordinary bistoury;

11-Fixation of the titanium implant;

12-Flap repositioning by drilling its central area to exteriorize the external implant area (Figure 4);

13-Flap suture with mononylon 4.0;

14-Curative with a silicon button and a petrolatum gauze; 15-External curative with a band.

While waiting for osseointegration, i.e., three months, the patient has returned four times to CDAHI for medical consultation, in which curative maintenance and phonoaudiological consultation were performed for purposes of guiding her how to take care and sanitize the pillar.

Processor placement and post-surgical evaluation

After three months after surgery, the patient has attended the phonoaudiological session to adapt the process and be guided how to handle and take care of BAHA. Open-field audiometry with pillar-coupled BAHA, external test and use of telephone were performed.

The distinction of words was evaluated after the surgery by using the same evaluation methodology used before the surgery (Table 1).

With regard to the complaint about tinnitus, the following results were observed:

- The tinnitus has started to have a low impact on her life, according to EVA's degree;

- There was a $47 \%$ reduction on THI's total score, mainly in the hearing and emotional aspects;

- As regards the patient's activities, it has been observed a 30\% reduction on the scores related to concentration, emotion and hearing.

In the handicap questionnaire, there was only a $3 \%$ reduction, however when the scores were separately compared regarding factor 1 , there was a $40 \%$ improvement,

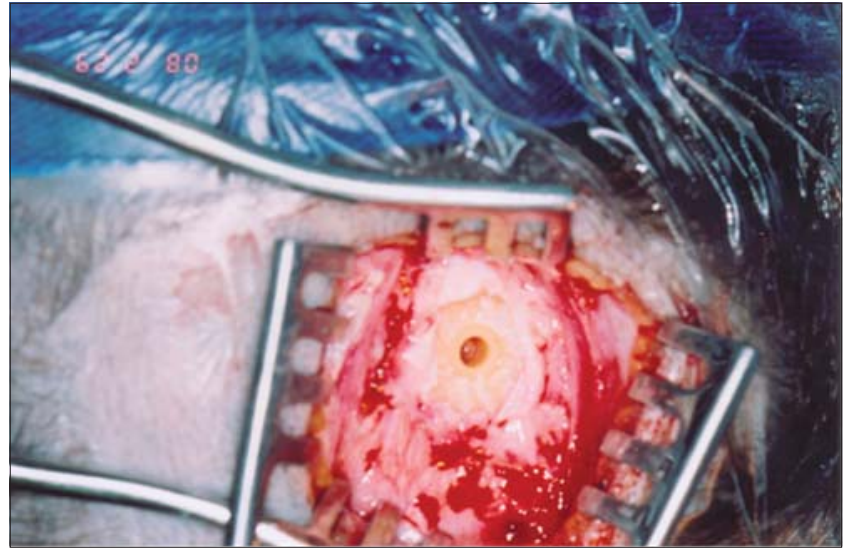

Figure 3. Bone drilling to couple the abutment.

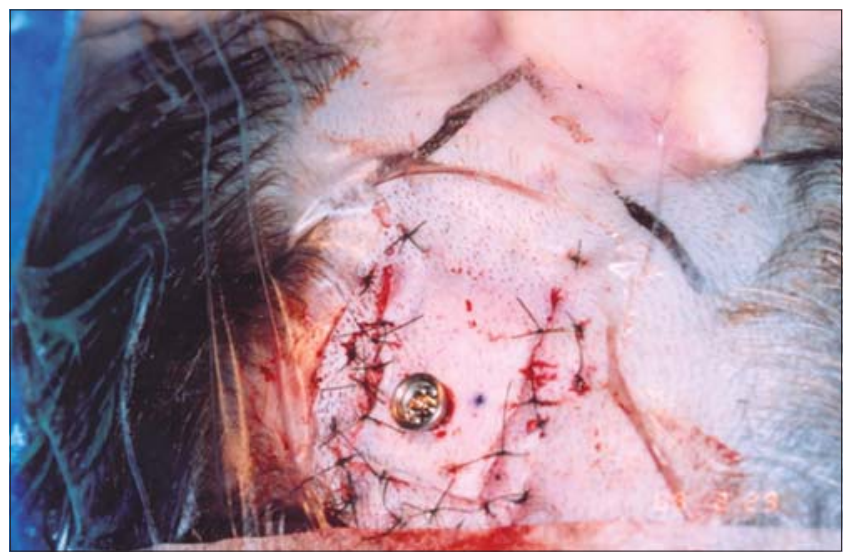

Figure 4. Flap repositioning by drilling its central area to exteriorize the external implant area.

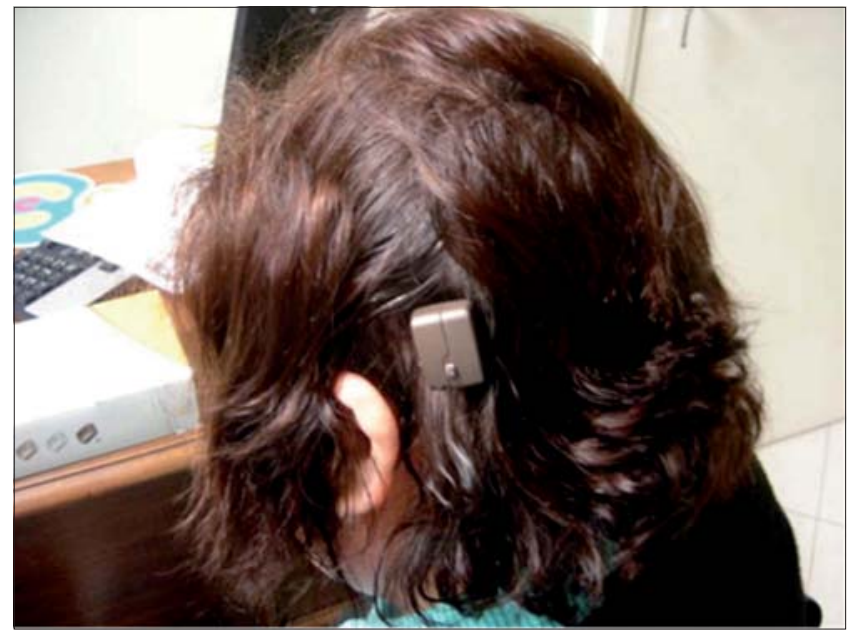

Figura 5. Abutment-coupled BAHA processor. 
Table I. Open-field threshold audiometry (dBNA) and percentile ratio of monosyllable recognition with a $65 / 60$ relation between signal and noise.

\begin{tabular}{lccccccc}
\hline Open-fieldaudiometry & $500 \mathrm{~Hz}$ & $1000 \mathrm{~Hz}$ & $2000 \mathrm{~Hz}$ & $3000 \mathrm{~Hz}$ & $4000 \mathrm{~Hz}$ & Average* & IPRF*** \\
\hline Noamplifiers & 70 & 50 & 50 & 20 & 20 & 47,50 & $84 \%$ \\
LEISAA & 35 & 25 & 25 & 25 & 30 & 27,5 & $92 \%$ \\
LEBAHAtester & 20 & 20 & 25 & 15 & 20 & 21,25 & $100 \%$ \\
LEBAHA & 30 & 20 & 20 & 15 & 15 & 21,25 & $100 \%$ \\
\hline
\end{tabular}

Legend:* Average between frequencies of $0.5,1,2$ and $3 \mathrm{kHz}$.

** Percentile index of speech recognition for monosyllables at $60 \mathrm{dBNA}$ on the left side with a concurrent noise at $55 \mathrm{dBNA}$ before the patient- $5 \mathrm{dBNA}$ signal-noise relation.

Table 2. Comparison between pre-surgical bone conduction (BC) thresholds and open-field air conduction thresholds when using abutment-coupled BAHA.

\begin{tabular}{lcccccc}
\hline & $500 \mathrm{~Hz}$ & $1000 \mathrm{~Hz}$ & $2000 \mathrm{~Hz}$ & $3000 \mathrm{~Hz}$ & $4000 \mathrm{~Hz}$ & Average* \\
\hline LEBoneconduction & 20 & 30 & 30 & 20 & 20 & 25 \\
LEBAHA & 30 & 20 & 20 & 15 & 15 & 21,25 \\
\hline
\end{tabular}

Legend:* Average between frequencies of 0.5, 1, 2 and $3 \mathrm{kHz}$.

and regarding factor 2, a $60 \%$ improvement. Accordingly, a worsening occurred in factor $3(57 \%)$.

The patient mentioned a lower perception of the tinnitus all the time when using the system and a lower perception of the tinnitus in the morning when waking up.

\section{DISCUSSION OF RESULTS}

In the cases of chronic otitis externa and open mastoid cavity, for occluding MAE, using ISAA mold can induce or worsen the infectious feature, leading to continual otorrhea (7). This makes BAHA an advantageous and better accepted tool for not using MAE molds (8), providing an effective and ongoing usage of sound amplification.

At present, various audiological evaluation methods have been used, but they have not been validated or verified for not having a standard evaluation protocol (14).

When comparing BAHA audiological results with those of ISAA, some authors show there is no difference in the audiometric results between each other $(9,10)$, however there are indications that the bigger the air-osseous interval (AOI), the bigger BAHA advantage is in comparison with ISAA (11). This advantage was observed in this case, mainly in 4,000-Hz frequency, where there was a 15-dBNA difference when using BAHA in comparison with ISAA. Additionally, an improvement occurred when distinguishing words, being $92 \%$ of right answers with ISAA and 100\% of right answers with BAHA. Another advantage BAHA has over ISAA was the use of telephone. The patient mentioned a great hearing comfort, with a better understanding on the phone, showing neither microphonia nor metallic voice caused by the hearing apparatus.

As to esthetics, she declares to be more comfortable with BAHA, because the people do not notice its presence as they used to notice ISAA.

When comparing the result of pre-surgical openfield audiometry, performed with BAHA tester, with the post-surgical one, performed with the implant-coupled BAHA, HAKANSSON et al., 1990 (9), reported to have better thresholds of airways with implant-coupled BAHA, and this difference can be between 2 and $15 \mathrm{dBNA}$, especially in acute frequencies where skin attenuation is bigger. In our evaluation, we observed it did not occur only in the 500$\mathrm{Hz}$ frequency, we had a worse 10 dBNA threshold with implant-coupled BAHA. In the 1,000 and $3,000 \mathrm{~Hz}$ frequencies, there was no difference between them both, and at 2,000 and $4,000 \mathrm{~Hz}$, our findings agree with the cited authors, as we observed better 5 dBNA thresholds with pillar-coupled BAHA, in comparison with the arch-coupled tester. Maybe we could have better thresholds with an implanted BAHA, if the adjustments used in the processor were the same as those in the pre-surgical evaluation, however it did not occur because the patient was discomforted when we adjusted the processor at a maximum gain, and we accordingly chose a lower gain adjustment, which would give her more comfort in the post-surgical evaluation. 
If we should analyze the average between the frequencies 50, 1,000, 2,000 and $3,000 \mathrm{~Hz}$, the pre-surgical and post-surgical thresholds are the same, what makes us trust the pre-surgical evaluation as a preview of the result that shall be achieved in the post-surgical period.

It has been observed that the airway thresholds on open-field audiometry with BAHA have exceeded the patient's best pre-surgical bone conduction, what Lustig and colleagues (5) refer to as 'overclosure'. This was observed in $30 \%$ of the cases evaluated in their studies.

Van Der Poun e col. Van Der Pouw and colleagues (6) explain that Divine BAHA can also gain as much as $10 \mathrm{~dB}$ in the sensorial component of the hearing loss, what was observed in our patient at 1,000 and 2,000-Hz frequencies, in which she had a 10-dBNA gain, and at 3,000 and 4,000 Hz, a 5-dBNA gain. (Table 2).

The AOI for less than $10 \mathrm{~dB}$ occurs in $80 \%$ of the cases with BAHA (12).

Both the suspension of vertigo and a significant reduction of tinnitus perception were observed in the questionnaires, complying with SÁNCHEZ-CAMÓN and colleagues' findings, and showing a positive effect of BAHA system on the tinnitus symptom (13).

\section{FinAL COMMENTARIES}

The surgery of BAHA implantation is a safe and easily performed procedure. Since it is a breakthrough in the Brazilian practice, a few difficulties were faced regarding this patient's audiological evaluation, for there is not a standardization of the methodology to be used. We suggest the exchange of experiences between the centers providing this service, so that by standardizing the audiological evaluation, we can compare results and pursue a better quality of service. The reliability in the pre-surgical audiological evaluation as a preview of the post-surgical result, the outstanding audiological results achieved, as well as the patient's high degree of satisfaction provided by BAHA system, turns it into an advantageous option to rehabilitate conductive and mixed hearing losses when ISAA is not possible to be used.

\section{BibliograpHICAL REFERENCES}

1. Branemark P, Breine U, Lindstrom J, et al. Intra-osseous anchorage of dental prostheses: I. experimental studies. Scand J Plast Reconstr Surg. 1969, 3:81-100.
2. Tjellstrom A, Lindstrom J, Hallen O, et al. Ten years of experience with the Swedish Bone Anchored Hearing System. Ann Otol Rhinoll Laryngol Suppl. 1991, 99:116.

\section{Audiological Manual Baha. Cochlear Américas.}

4. Hakansson B, Tjellstrom A, Rosenhall U. Hearing thresholds with direct bone conduction versus conventional bone conduction. Scand Audiol. 1984, 13(1):3-13. Audiological Manual.

5. Lawrence R L, Alexander A, Derald E, et al. Hearing Rehabilitation Using the BAHA Bone anchored Hearing Aid: Results in 40 patientes. Otology e Neurotology. 2001, 22:328-334.

6. Van Der Pouw CTM, Mylanus EAM, Cremers CWRJ. Percutaneus implant in the temporal bone for securing a bone conductor. Surgical methods and results. Ann Otol Rhinol Laryngol. 1999, 108:532-537.

7. Snik AF, Mylanus EA, Cremers CW. The bone-anchored hearing aid: a solution for previously unresolved otologic problems. Otolaryngol Clin North Am. 2001, 34(2):36572.

8. Snik AF, Mylanus EA, Cremers CW. Bone Anchored Hearing Aids in patients with sensorioneural hearing loss and persistrent otitis externa. Cion Otolaryngol. 1995, 20(1):31-5.

9. Hakansson B, Liden G, Tjellstrom A, Ringdahl A, Jacobsson $M$, Carlsson P, Erlandson BE. Ten years of experience with the Swedish bone-anchored hearing system. Ann Otol Rhinol Laryngol Suppl. 1990, 151:1-16.

10. Bance M, Abel SM, Papsin BC, Wade P, Vendramini J. A comparison of the audiometric performance of bone anchored hearing aids and air conduction hearing aids. Otol Neurotol. 2002, 23(6):912-9.

11. Mylanus EAM, Van Der Pouw CTM, Snik AFM, Cremers CWRJ. An Intra-individual comparison of the BAHA and airconduction hearing aids. Arch Otolaryngol Head Neck Surg. 1998, 124:271-276.

12. Lustig LR, Arts HA, Brackmann DE, Francis HF, Molony T, Megerian CA, Moore GF, Moore KM, Morrow T, Potsic W, Rubenstein JT, Srireddy S, Syms CA 3rd, Takahashi G, Vernick D, Wackym PA, Niparko JK. Hearing rehabilitation using the BAHA bone-anchored hearing aid: results in 40 patients. Otol Neurotol. 2001, 22(3):328-34.

13. Sánchez-Camón I, Lassaletta L, Castro A, GavilánJ. Quality 
of life of patients with BAHA. Acta Otorrinolaringol Esp.

2007, 58(7):316-20. 